\title{
Movimentos da paisagem na poesia de João Cabral de Melo Neto
}

\author{
Regina Célia dos Santos Alves \\ Universidade Estadual de Londrina
}

\begin{abstract}
Resumo
A partir do conceito de paisagem enquanto percepção de um espaço, cuja dinâmica ocorre na inseparabilidade entre sujeito, lugar e figuração, pretende-se, no presente trabalho, abordar a paisagem em três poemas sobre os cemitérios pernambucanos publicados em Paisagens com figuras, de João Cabral de Melo Neto. Cada cemitério, pertencente às cidades de Toritama e de São João da Mata, desdobra-se em diferentes paisagens a partir da perspectiva pela qual é percebido pelo sujeito lírico. Para as diferentes imagens criadas, colaboram aspectos da geografia, da história, da economia, da cultura, dos hábitos e costumes do local filtrados pela sensibilidade estética do poeta que, com as paisagens construídas, consegue expressar de forma pujante a intensidade do ser, viver e morrer do homem nordestino.
\end{abstract}

Palavras-chave: João Cabral de Melo Neto; paisagem; cemitério; vida; morte.

\begin{abstract}
From the concept of landscape as perception of a space, whose dynamics occurs in the inseparability between subject, place and figuration, in the present paper we intend to approach the landscape in three poems about the cemeteries of Pernambuco published in Paisagens com figuras, by João Cabral de Melo Neto. Each cemetery, belonging to the cities of Toritama and São João da Mata, unfolds in different landscapes from the perspective by which it is perceived by the lyrical subject. For the different images created, aspects of the geography, history, economy, culture and customs of the locality, filtered by the aesthetic sensibility of the poet who, with the constructed landscapes, manage to express in a powerful way the intensity of being, living and dying of the Northeastern man.
\end{abstract}

Keywords: João Cabral de Melo Neto; landscape; cemetery; life; death.

Recebido em: 31/03/19

Aprovado em: 08/06/19

Na poesia de João Cabral de Melo Neto (poesia esta que se faz como pedra, solidez quase impenetrável, faca afiada, capaz de alcançar o âmago das coisas, arquitetura de palavras e sentidos transbordantes), os caminhos de abordagem e de entendimento multiplicam-se muito menos pela opção do crítico por algum viés de análise e interpretação dado de antemão e que 
encontre abrigo nos textos do escritor que pela própria natureza da poesia cabralina. Esta, na sua engenhosidade compositiva e criativa, oferece-se como um universo denso e profundo, a abrir um leque amplo de possibilidades de leitura, que parece jamais chegar a um esgotamento, dada a existência sempre presente de um elemento novo, palpitante, a instigar novos olhares, ainda que o novo se faça, como mostra Luiz Costa Lima, por meio de círculos e não de saltos: "Uma parte da outra se alimenta, aquela por esta evolui e esta evolução se mostra como distensão daquela" (1968, p. 328).

Nessa linha de raciocínio, a paisagem aparece como um desses elementos colocados pela própria poesia do autor, da qual é difícil escapar, ou mesmo desviar, quando se pretende um estudo mais atento da literatura de João Cabral de Melo Neto, pois se instaura como um dos fundamentos de sua poesia, não apenas porque nela é possível vislumbrar cenários caros ao poeta que se referem ao universo nordestino, particularmente pernambucano, na sua peculiaridade geográfica e humana, mas, sobretudo, por se revelar como um modo de viver e não apenas habitar o espaço, mostrando-se como "unidade perceptiva e estética, mas [...] também unidade aberta de sentido" (COLLOT, 2013a, p. 214).

Como mostra Rafaela de Abreu Gomes, o elemento tópico é uma presença marcante na poesia do escritor pernambucano, cuja literatura desvela "a necessidade de falar a partir de seu próprio lugar, o Recife" (2015, p. 19), mesmo que dele esteja distante. A produção do autor, assim, expressa o exercício sensível, delicado, engenhoso e árduo de transformar em poesia paisagens com as quais vivia (GOMES, 2015), combinando de maneira muito peculiar mesmo as aparentemente mais díspares, mas que, de todo modo, como mostra Luiz Costa Lima, pudessem "ressaltar mais nítido o que é núcleo de seu núcleo: certa ideia de homem" (1968, p. 336-7).

Nesse sentido, na poesia cabralina, a paisagem parece ser um dos lugares onde essa "certa ideia de homem", sobretudo do homem e da vida nordestina, ou melhor, "severina", pulsa com intensidade desmedida, no significar a paisagem que é o trabalho do poeta. Como afirma Maurice Merleau-Ponty, "sou eu quem faz ser para mim" (2014 p. 3) e, nesse movimento de construção do sentido das coisas, a poesia de João Cabral cria um sentido específico para suas paisagens, jamais presas ao mimetismo ou a qualquer apelo de natureza meramente pitoresca, que poderia levar ao que facilmente tem caracterizado certo regionalismo de epiderme, de forte expressão exótica. Nele, a paisagem é, antes de tudo, uma revelação do ser, do viver e do sentir, como também, ao que parece, uma forma de pensamento e de conhecimento. Nas paisagens de João Cabral está sempre, ainda de acordo com Luiz Costa Lima (1968), uma preocupação com o homem, nelas marcadamente implícito, sendo que sua expressão converge para sua explicitação mais bravia.

A partir do conceito de paisagem enquanto imagem do mundo, necessariamente composta por um lugar, um olhar e uma imagem (COLLOT, 2013b, p. 17), a qual se constrói por meio de "una lógica de la identidad del predicado" (BERQUE, 2009, p. 114), de viés subjetivo, portanto, e não de identidade do sujeito de ordem objetiva, como costumeiramente 
tem marcado nosso paradigma ocidental moderno do conhecimento, ${ }^{1}$ é que pretendemos ler a série de poemas cabralinos intitulados "Cemitérios pernambucanos", presentes em Paisagens com figuras (1954-1955).

A paisagem do cemitério reiteradamente aparece na produção literária de João Cabral de Melo Neto e parece ter um papel significativo naquilo que encerraria sua poesia: a direção humanista, de tom bastante singular:

Pois em Cabral tratamos com um humanismo agressivo, não complacente. Humanismo de quem se recusa a escrever quando não sente forças para a luta. Tão agressivo que imagina um intestino das lâminas, seu "avesso do nada", intestino de fome, que arde no uso da faca" (LIMA, 1968, p. 336, grifo do autor).

$\mathrm{Na}$ paisagem, esse local por excelência da percepção, da "iniciação ao mundo" (MERLEAU-PONTY, 2014 p. 346), o humanismo cabralino de que fala Luiz Costa Lima encontra seu melhor lugar. Na série "Cemitérios pernambucanos", o poeta explora com maestria a intensidade da paisagem, fazendo dela "uma medida do mundo" (COLLOT, 2013b, p. 205).

Em Paisagens com figuras (1954-1955), João Cabral de Melo Neto compõe três poemas cujo enfoque é o cemitério; "Cemitério pernambucano" (Toritama), "Cemitério pernambucano" (São Lourenço da Mata) e "Cemitério pernambucano" (Nossa Senhora da Luz). Em todos eles, embora o próprio título aponte para certa fixidez da paisagem, centrada no cemitério de determinados lugares geograficamente constituídos, chama a atenção a dinâmica das paisagens do autor - construídas a partir do princípio do movimento, da movência, da articulação de imagens e sentidos inusitados —, que se revelam como lugar da aglutinação e, ao mesmo tempo, do particular.

É mais uma vez o comentário de Luiz Costa Lima - aqui já citado à exaustão, mas justamente pela justeza e propriedade de seu pensamento sobre a produção do autor de Morte e vida severina - que parece esclarecer o processo constitutivo da poesia de João Cabral e, consequentemente, da paisagem. Considerando que a poesia do autor ocorre por círculos, e não por saltos, chama atenção para o aspecto intercambiável e dialético apresentado por seu fazer poético:

É certo que, mesmo por conta do desenvolvimento por círculos, será impossível deixar-se de referir por completo ao que já poderia estar compreendido. A questão que por conseguinte aqui se põe é a de saber delinear o que pareça o núcleo radical da obra, que se transforma, conservando seus meios operativos próprios. Melhor do que

\footnotetext{
${ }^{1}$ De acordo com Augustin Berque, a paisagem define-se como visão cosmológica e complexa a seguir em direção contrária ao que chama de paradigma ocidental moderno do conhecimento, pautado pela neutralidade, pela geometria e pelo traço mecânico e quantitativo, capaz de "reducir el mundo exterior a un objeto" e de "reducir el paisaje a una proyección arbitrária de uno mismo sobre este objeto" (2009, p.18).
} 
isso: verificar que tais elementos de permanência e variação não vivem segregados, como a parte acalmada e a parte em movimento de um organismo. Porquanto a própria distinção não tem sentido no poeta. Uma parte da outra se alimenta, aquela por esta evolui e esta evolução se mostra como distensão daquela. A imagem mais apropriada é a da bola de neve que rola pela montanha, a cada volta acrescendo a bola que já é (LIMA, 1968, p. 328).

Esta construção hologramática é a que encontramos na série de poemas sobre cemitérios pernambucanos, dos quais aqui nos ocuparemos. João Cabral "parte de uma tópica e, dela, constrói relações com outros assuntos, num equilíbrio que permite à tópica e a suas ligações coexistirem no mesmo plano de importância [...]" (GOMES, 2015, p. 15).

Nos três poemas da série, "Cemitério pernambucano" (Toritama), "Cemitério pernambucano" (São Lourenço da Mata) e "Cemitério pernambucano" (Nossa Senhora da Luz) tem-se, de início, e de maneira bastante precisa, a marcação de um lugar determinado e constante nos três poemas já exposto nos títulos: o cemitério pernambucano. É dessa paisagem basilar que outras vão surgir e a ela retornar, num movimento ininterrupto e indissociável. Vale lembrar que nos três poemas a paisagem é a medida para o alcance daquilo que, de toda maneira e sempre, movimenta a poesia do autor: "certa ideia de homem" (LIMA, 1968).

"Cemitério pernambucano" (Toritama) define um lugar geográfico particular, Toritama, município do agreste pernambucano e distante do litoral. É um olhar para o cemitério desse local, portanto, que será revelado pelo poema. Por meio da justeza e da precisão peculiar à construção poética de Cabral, esse cemitério de Toritama apresenta uma paisagem nada convencional ou prevista.

Ao contrário do que se poderia esperar, posto que o título do poema põe em cena um espaço, não há descrição de pormenores acerca do cemitério, com exceção de quatro elementos, desencadeadores do movimento semântico e imagético que percorre o poema: o muro, as tumbas, as grades de ferro e o cadeado. Na perspectiva hologramática de construção cabralina, já mencionada em outros momentos, esses elementos básicos constitutivos da paisagem do cemitério abrem caminho para a dinâmica do poema, assentada nas interrogações organizadas nas três primeiras estrofes e que levam à possível resposta na última estrofe:

Para que todo este muro?

Por que isolar estas tumbas

do outro ossário mais geral

Que é a paisagem defunta?

A morte nesta região gera dos mesmos cadáveres?

Já não os gera de caliça?

Terão alguma umidade? 


\author{
Para que a alta defesa, \\ alta quase para os pássaros, \\ e as grades de tanto ferro, \\ tanto ferro nos cadeados? \\ - Deve ser a sementeira \\ o defendido hectare, \\ onde se guardam as cinzas \\ para o tempo de semear \\ (MELO NETO, 1997, p. 128).
}

Duas questões se apresentam de início: qual a finalidade do muro, alto "quase para pássaros", e por que a separação entre uma paisagem e outra conseguida por meio do muro? Nessas questões estão dois aspectos fundamentais no poema, a materialidade da paisagem por meio de alguns elementos e o sentido simbólico adquirido pela mesma.

$\mathrm{Na}$ construção paralelística de início apresentada, o cemitério, depósito de tumbas, se dá a ver na sua semelhança com uma paisagem outra, mais ao alcance do olhar do sujeito lírico, posto que escancarada no mundo, do "ossário mais geral”, que recobre toda a paisagem externa. Igualmente a do cemitério, é também uma "paisagem defunta".

A proximidade entre as duas paisagens, a do cemitério e a geral, ocorre em dois sentidos. O primeiro é de ordem mais objetiva e as tumbas funcionam como uma espécie de continuidade da paisagem seca, sem vida que compõe a vegetação do lado externo, aberto do cemitério, haja vista a particularidade de localização deste cemitério pernambucano, que é Toritama, situada em pleno agreste de Pernambuco. Nesse sentido, o poema promove a fusão das duas paisagens por meio de um jogo especular dos elementos que a compõem, as tumbas e os ossos das vidas ceifadas - a que o cemitério serve de depósito - , e a vegetação seca, dura e escurecida da caatinga, sem nenhuma cor de vida, que o espaço mais amplo serve de depósito, daí a "paisagem defunta", a alongar-se para além dos muros altos e das grades de ferro trancadas a cadeado que inutilmente o cemitério, enquanto espaço de morte, parece tentar conter com seu aparato de fechamento.

O segundo sentido, de ordem metafórica, emerge justamente do primeiro e põe em cena a problemática humana e social que atravessa a poesia de João Cabral de Melo Neto. O cemitério, assim, não se reduz ao espaço construído para abrigar os mortos que naturalmente deixariam de viver, nem a "paisagem defunta" seria apenas a materialidade geográfica do sertão nordestino. Na verdade, ambos nos encaminham não para a morte propriamente, mas para a condição de vida no lugar que, ironicamente, é uma condição de morte, afirmada já no próprio questionamento trazido pelo sujeito lírico: "A morte nesta região/gera dos mesmos cadáveres?" (p. 128). Numa inversão da lógica, a morte gera da própria morte e não da vida, “— Deve ser a 
sementeira/o defendido hectare, /onde se guardam as cinzas/ para o tempo de semear" (p. 128) —, pois tudo é morte (sementes de cinza) e o homem está, assim como a paisagem petrificada da caatinga, reduzido ao estado de "ossário", sem qualquer sopro de "umidade", de vida, na trágica condição de desproteção - não dispõe dos muros, das grades e dos cadeados do cemitério à mercê das vicissitudes da vida "severina" a que está sujeito natural e socialmente, que lhe reserva apenas sementes de cinza, sementes de morte.

Ao final, a voz da conclusão expressa a constatação desde o início anunciada pelo poema nos questionamentos que já traziam em si a resposta: a certeza da vida que é morte, da paisagem desfigurada de vida - sólida, fria, dura - como os muros, as tumbas, as grades, os cadeados do cemitério, enfim, "paisagem defunta".

Da solidez e estaticidade que compõem a imagem do cemitério de Toritama, passa-se a ideia de movimento e liquidez no cemitério de São Lourenço da Mata, o segundo da série em Paisagens com figuras. Neste, chama a atenção a agudeza da construção hologramática, do movimento "bola de neve" de que fala Luiz Costa Lima, pois que o sentido se forma na relação contínua e indissociável entre as partes.

No cemitério de São João da Mata - município pertencente à região metropolitana do Recife, situado no litoral, portanto - , o princípio da analogia entre diferentes paisagens, à primeira vista sem qualquer traço de identidade, norteia toda a construção do poema por meio de um olhar que consegue ver, para além do que a visão permite, semelhanças capazes de levar a uma ideia aguda da condição do homem, sobretudo, mais uma vez, do homem nordestino. É com as paisagens familiares do universo de vida do nordeste que o poeta cria outra, ao mesmo tempo delas próxima e distante.

Exemplar na construção de relações, no movimento de vai-e-vem de uma palavra à outra, de um sentido ao outro, de uma imagem à outra, "Cemitério pernambucano" (São João da Mata), composto por quatro estrofes, aproxima o cemitério a outras paisagens. Na estrofe inicial, a analogia central, que reiteradamente vai sendo recolocada no poema, aparece no atributo dado ao cemitério: "marinho". Fundem-se, nesse momento do texto, a imagem de cemitério, mar e canavial:

É cemitério marinho mas marinho de outro mar. Foi aberto para os mortos Que afoga o canavial.

As covas no chão parecem as ondas de qualquer mar, mesmo as de cana, lá fora, lambendo os muros de cal. 
Pois que os carneiros de terra
parecem ondas de mar,
não levam nomes: uma onda
onde se viu batizar?
Também marinho porque
as caídas cruzes que há
são menos cruzes que mastros
quando a meio naufragar
(MELO NETO, 1997, p. 130).

No jogo de aproximação e distanciamento, esses três elementos - cemitério, mar e canavial - se inter-relacionam por meio da ideia de movimento e morte. Se o cemitério por si só já carrega em primeira instância a morte, o mar e o canavial são trazidos para a aproximação porque vistos potencialmente como portadores de sentido semelhante. Assim, tanto o mar quanto o canavial "afogam": literalmente, o mar, com a água, e, metaforicamente, o canavial, com o trabalho duro e exaustivo, a explorar de forma desmedida a força do trabalhador em seus mares de verde a perder de vista. Tanto o mar quanto o canavial levam, desse modo, à ideia de morte e, por consequência, à de cemitério.

$\mathrm{Na}$ segunda estrofe, a aproximação do cemitério com o canavial ocorre de maneira mais intensa, especialmente pela exploração da ambiguidade do termo "covas": no cemitério, as covas para os mortos, onde são depositados, a "cova miúda", ironicamente a parte maior que lhe cabe no latifúndio da vida e da terra, como se observa em Morte e vida severina; no canavial, as covas da plantação, onde está implícita a ação humana de plantar, de lavrar um latifúndio que não lhe pertence, que o explora e o leva à cova da morte.

De igual maneira, essas covas também nos reportam à paisagem marítima — “As covas no chão parecem/ as ondas de qualquer mar", naquilo que têm de sua aparência material, ou seja, certa elevação no plano da água (onda) e no plano da terra (cova). A partícula explicativa "pois", que introduz a terceira estrofe, alimenta ainda mais a analogia construída passo a passo entre o cemitério, o canavial e o mar posta desde o início do poema. Nela, João Cabral joga interessantemente com o termo "carneiros" - que significa espumas de onda, elevações na superfície da água - , ao tirá-lo de seu lugar comum, a água, e levá-lo para o local inusitado, a terra, pois os carneiros visualizados são de terra. Dessa maneira, aproxima ainda mais as paisagens supostamente distantes - o cemitério, o mar e o canavial — fazendo com que se fundam de modo indissociável.

Os "carneiros", assim, são do mar (ondas), mas também da terra, covas do cemitério e do canavial, ondas e covas tão anônimas quanto as vidas que ali encerram, visto que, como ironicamente mostra o poema, "não levam nomes: uma onda/onde se viu batizar?" (p. 130). Portanto, o homem, implícito nos carneiros/covas, iguala-se a um outro fenômeno qualquer 
da natureza e nada há que o distinga na "paisagem defunta" - seja ela seca e dura como a da caatinga, líquida como a do mar ou movente como a do canavial no embalo do vento - , muito menos um nome, premiação talvez maior do ser humano, traço do qual está desprovido: se cova, terra ou onda, não necessita de batismo.

Se o cemitério de São Lourenço da Mata assemelha-se ao mar e ao canavial pelas possibilidades analógicas que o poema constrói no âmbito da materialidade e do sentido, ao final uma nova aproximação entre as cruzes do cemitério e os mastros do navio apresenta-se de forma definitiva. Em São Lourenço da Mata, o cemitério é marinho, não apenas porque guarda os "afogados" do canavial, mas "também marinho" porque as cruzes caídas das sepulturas remetem aos mastros que afundam durante o naufrágio, o qual, por sua vez, leva à ideia de corte, de ceifar de uma caminhada que afunda indelevelmente nas profundezas da água, assim como as cruzes do cemitério expressam as vidas ceifadas pela força tempestuosa da exploração, da miséria, do anonimato, do trabalho árduo, das desigualdades da condição "severina" do homem nordestino pobre, "igual em tudo na vida", igual "em tudo e na sina" (MELO NETO, 1997, p. 146).

As cruzes e os mastros, dessa maneira, são transformados em elementos de identificação e de indissociabilidade entre a paisagem do cemitério e a paisagem do mar, tanto naquilo que visualmente as aproximam — cruzes e mastros — quanto pelo significado simbólico desses elementos que o poema explora por meio de aguda sensibilidade poética.

Por fim, o último poema da série, "Cemitério pernambucano" (Nossa Senhora da Luz), constrói a imagem do cemitério enquanto abrigo para, ao que parece irônica e paradoxalmente como em Morte e vida severina, trazer a morte como única condição verdadeira do homem, seja porque está, enquanto existente, condenado a esse fado, seja porque nela passa a pertencer à terra e por ela ser acolhido.

O poema inicia-se com uma afronta ao senso comum, ao desfazer a ideia de que o cemitério é um depósito de corpos mortos que ali jazem (deitam sobre o chão):

\footnotetext{
Nesta terra ninguém jaz, pois também não jaz um rio noutro rio, nem o mar é cemitério de rios.

Nenhum dos mortos daqui vem vestido de caixão. Portanto, eles não se enterram, são derramados no chão.

Vêm em redes de varandas abertas ao sol e à chuva. Trazem suas próprias moscas. O chão lhes vai como luva.
} 
Mortos ao ar livre, que eram,

hoje à terra-livre estão.

São tão da terra que a terra

nem sente sua intrusão

(MELO NETO, 1997, p. 132-133).

Simetricamente ao rio e ao mar, proximidade já antes expressa nos poemas anteriores, onde um rio não jaz em outro e nem no mar jazem as águas de outros rios — posto que sua essência, a água, se mistura de forma indissolúvel, não havendo nenhuma fronteira a delimitar o espaço e a natureza de uma ou outra —, na terra do cemitério também “ninguém jaz".

Morto, o homem comum, pobre, "posto em redes de varandas/abertas ao sol e à chuva e que carrega "suas próprias moscas", desnudado da vida, de seus adornos e barreiras (o caixão, por exemplo, que funcionaria como um objeto de isolamento entre o homem e a terra e que apontaria ainda para certas condições materiais de vida e de morte, negadas ao sujeito marginalizado) vai ao encontro daquilo que lhe resta e que parece ser sua condição última: a organicidade da terra.

Assim, não é "enterrado", coberto de terra, como se ainda mantivesse uma essência estranha ao objeto último que lhe servirá de morada, mas "derramado" no chão, como se fosse líquido, como a água do rio que se derrama em outro rio, como a água do rio que se derrama no mar.

No "derramar-se no chão", o poema de João Cabral iguala o morto à terra, assim como a água de um rio à de outro, a do rio à do mar. A ela se mistura sem as ramas (de-ramado) do antropomorfismo, transformado em pó que ao chão se mescla e onde não mais encontra a diferença, o limite, a distinção, em vida possivelmente origem do sofrimento. Não por um acaso, "o chão lhes vai como luva", sinônimo de abrigo, do acolhimento, do sentir-se em casa.

Diferentemente do caixão - para os mais abastados e que supostamente continuaria a manter o isolamento do homem em relação à natureza mesmo depois de morto —, o chão-luva não é proteção contra a terra, contra o supostamente estranho, mas pertencimento, posto que o homem nela se encontra e com ela se familiariza, terra que o "abriga" e o "veste" (p. 160) do abandono e do desnudamento social a que se achava condenado em vida, sendo de terra sua "derradeira camisa", que o veste "como nunca em vida" (p. 160)

Vivos, os homens estão "mortos ao ar-livre", jogados à sorte do desamparo e da desproteção, sob o sol e a chuva, lançados às agruras de uma sociedade desigual — na incontida suposta liberdade (ar-livre) — da severa vida severina, mais morte que vida, "aquela que é menos/ vivida que defendida" (MELO NETO, 1997 p. 153). Pertencem à terra (buscada, desejada, sonhada, sentida) que só fora da vida alcançam num processo de simbiose: "São da terra que a terra/ nem sente sua intrusão". A “terra-livre" é de todos, indistintamente, pois a ela o corpo se mistura, já que também é terra. 
Só na morte, portanto, a liberdade é alcançada. Contraria e paradoxalmente, o "ar-livre", na contramão da terra, do chão, revela-se na condição desabrigada do homem nordestino, cujo presente, passado e futuro resumem-se ao sofrimento e à morte. Ao ar-livre, parece tornar-se um intruso, ao passo que à terra-livre encontra seu lugar e dela passa a fazer parte.

Desse modo, no processo criativo de João Cabral, é possível ver a paisagem enquanto um conhecimento holístico, que traduz a relação dinâmica entre o sujeito e o mundo, constituindo aquilo que para Berque é a manifestação de um verdadeiro "pensamiento pasajero": "Y el pensamiento pasajero es la forma como cada ser humano, con su carne e con sus acciones, traduce esta medianza” (2009, p. 103), ou seja, a relação, o intercâmbio do sujeito com seu entorno.

Em síntese, é possível pensar que nos três cemitérios pernambucanos de Paisagens com figuras a potencialidade da paisagem enquanto percepção de um espaço a apontar para um modo de ser, viver e sentir apresenta-se de modo pungente. Partindo do visível, do que está ao alcance do olhar, os poemas de João Cabral projetam possíveis paisagens outras, ocultadas pela linha do horizonte visível, mas que, animadas não apenas pelo olho, mas sobretudo pelo espírito, revelam-se e tornam-se também verdadeiras. Assim, por detrás dos cemitérios, dos muros, das covas, das cruzes, dos ossários, descortina-se uma paisagem humana, em especial aquela do homem nordestino pobre, marginalizado, composta pelo anonimato (as ondas não têm nome), pela miséria (o ossário geral que se vê por toda parte), pela ausência de esperança (os mastros que se afundam em um naufrágio), pela brutalidade do trabalho desmedido (o afogamento dos canaviais), enfim, pelo modo de ser Severino de vida e de morte.

\section{Referências}

BERQUE, Augustin. El pensamiento pasajero. Tradução: Maysi Veuthey. Madrid: Biblioteca Nueva, 2009.

COLLOT, Michel. Do horizonte da paisagem ao horizonte dos poetas. In: ALVES, Ida; FEITOSA, Márcia Manir Miguel (Orgs.). Literatura e paisagem. 2. ed. Niterói: Editora da UFF, 2013a.

. Poética e filosofia da paisagem. Tradução: Ida Alves et al. Rio de Janeiro: Oficina Raquel, 2013b.

GOMES, Rafaela de Abreu. João Cabral, um poeta-crítico: poiesis e crítica. 2015. $163 \mathrm{f}$. Dissertação (Mestrado em Letras) — Universidade Federal do Ceará, Fortaleza, 2015.

LIMA, Luiz Costa. Lira e anti-lira. Rio de Janeiro: Civilização Brasileira, 1968.

MELO NETO, João Cabral de. Serial e antes. Rio de Janeiro: Nova Fronteira, 1997.

MERLEAU-PONTY, Maurice. Fenomenologia da percepção. Tradução: Carlos Alberto Ribeiro de Moura. São Paulo: Martins Fontes, 2014. 


\section{Minicurrículo}

Regina Célia dos Santos Alves é professora associada de Literatura Brasileira do Departamento de Letras Vernáculas e Clássicas da Universidade Estadual de Londrina/Paraná. 